\title{
Chemistry for the non-science student
}

\author{
A.P. Zipp \\ Inside Chemistry. By Charles Compton. \\ Pp.569. (McGraw-Hill: New York and \\ London, 1979.) $\$ 16.95$.
}

IN the words of the author, this text was written to "meet the special needs and interests of nonscience students" while having enough flexibility to "provide the basis for courses; with different emphases, levels and lengths"'. In my opinion he has been reasonably successful in achieving his goals, although the book has limitations.

On the positive side, the selection of topics seems sufficiently broad to satisfy most instructors, although several lack depth (see below). The text is divided into eight chapters (297 pages) of 'core' material and seven chapters ( 200 pages) of 'applied' topics, with each of the latter being independent of the others so that they may be studied in any order or combination. In addition, most chapters contain optional sections and the bulk of the quantitative material has been gathered into supplements at the end of the text. These features should allow each instructor to adapt the book to his own course.

The book is written at an appropriate level and the examples used should be of interest to the intended audience. The learning process should be enhanced by the self-study questions (with answers), the practice exercises (without answers), and the key word lists which follow each chapter as well as the excellent glossary at the end of the text. The data and statistics are as current as could be expected, a point which is particularly important for environmental courses, and each chapter has a list of relevant references (some as recent as 1977).

On the negative side, the book is occasionally redundant, although this occurs mostly in the later chapters which are intended to be independent of one another (for example, photosynthesis is discussed in three different places and production of carbon monoxide in two). More seriously, some discussions lack sufficient depth to be understood readily. Specific examples include Dalton's atomic theory, the greenhouse effect, base pairing in nucleic acids, oral contraceptives, and amino acid balance in foods. Although this can be remedied in lecture, it may be distressing to students who consider a text to be the final authority, and instructors who feel similarly may wish to select a book designed for a course with a particular emphasis (for example, environmental or biochemical).

In summary, this is a potentially useful text with enough strong points to justify its consideration by instructors of non-science major courses but should be recognised as one which will require supplementary work by the teacher in many areas.

A.P. Zipp is Professor of Chemistry at the State University of New York at Cortland.

\section{Aquatic insects}

\section{A.A. Grigarick}

An Introduction to the Aquatic Insects of North America. Edited by R.W. Merritt and K.W. Currins. Pp.441. (Kendall/Hunt: Dubuque, Iowa, 1978.) $\$ 21.95$.

AQUATIC insects have been receiving a great amount of attention from many scientific disciplines for the past 20 years. During this period a considerable number of taxonomic changes, new information on distribution, and ecological studies on aquatic insects have occurred. Merritt and Cummins have gathered the contributions of an impressive group (21) of scientists to incorporate much of this information into An Introduction to the Aquatic Insects of North America. The book was directed at both students and professionals of the many fields that deal with the aquatic habitat and the authors do not assume the reader to have an entomological background.

The first chapter explains the make-up of the book, indicates its limitations and presents an annotated list of general taxonomic references dealing with aquatic insects. Enough general morphology is given in Chapter 2 to lay the groundwork for use of the keys. Chapter 3 is devoted to collecting, sampling and rearing methods which are tabulated by habitat and community. This chapter includes an amazing amount of information in a well organised and concise form and it is well documented with source material and illustrations.
A short chapter on ecology and distribution sets the format for the handling of this information in later chapters at the generic level in each order. The tabular presentation of information includes habitat classification, locomotive behaviour, trophic relations (based on feeding mechanism) and distribution. By necessity, this information is often based on generalisations of limited numbers of species but when it is used in this light and with the supporting references it is of considerable value. In table $4 \mathrm{C}$ some of the examples of orders used to demonstrate trophic classification and columns of the classification are either out of alignment or wrongly set up at the printers. The reader should obtain this information directly from the trophic relationships presented at the end of the chapter for each order.

Phylogenetic relationships and evolutionary adaptations of aquatic insects are briefly reviewed in Chapter 5. Chapter 6 takes up the entomological basics of classification and metamorphosis and a key to immatures and adults is given for the orders with aquatic or semi-aquatic insects. These orders are taken up in a phylogenetic sequence in the remaining chapters. A general introduction, pertinent external xz orphology and keys to the family for immatures and adults are given for each order. Key characters are usually well illustrated and additional taxonomic references follow the keys. Each chapter concludes with a tabular summary of ecological and general distributional information at the generic level.

The keys to Megaloptera, Neuroptera and Lepidoptera (in part) allow identification to genus. About one-third of the book deals with the aquatic Diptera and includes separate chapters on the Tipulidae, Culicidae, Simuliidae and Chironomidae. The expanded treatment of these families includes keys to immatures and adults to genus for the first three but is limited primarily to tribe for the chironomids. The limitation of the taxonomic treatment to the family level for most orders was disappointing to many researchers and instructors of courses in aquatic entomology. With due respect to the large size of this group of organisms and incomplete knowledge of some taxa (for example, Diptera), the taxonomic information for identification to the generic level has been developed for most families. Identification to genus would certainly be desirable in this book and would appear to have been possible if a comparable amount of effort had been made in this direction as was devoted to summarising ecological information to genus.

As the title states, the region of this book's coverage is North America. However, the great diversity of aquatic insects in North America (over 10,000 species), the degree of ecological coverage, excellent illustrations and extensive source material $(1,712$ references $)$ make this book very useful to aquatic biologists throughout the world. It is particularly welcomed by instructors of the subject.

A.A. Grigarick is Professor of Entomology at the University of California, Davis, California. 